\title{
2
}

\section{EMPLOYEE RESOURCING: \\ THE PLANNING AND RECRUITMENT PHASE}

Marian Crowley-Henry

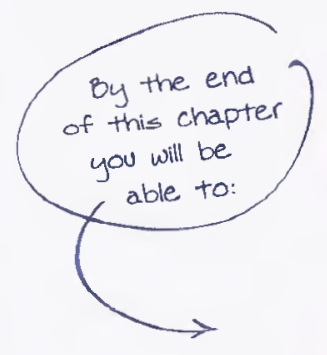

LEARNING OUTCOMES

o Outline the nature of human resource planning (HRP) and how HRP links with the organization's overall business strategy and its specific recruitment strategy

- Describe the stages in the HRP process and recognize the importance of ongoing $H R$ planning in organizations

- Differentiate recruitment from selection activities within an organization's resourcing strategy

- Explain the advantages and disadvantages of different recruitment methods

- Describe ways of generating an 'applicant pool' and attracting candidates

o Identify what a flexible workforce is and how organizations use it

- Explain key legislation in relation to recruitment and the flexible workforce

- Distinguísh between terms used in recruitment, such as 'job analysis', 'job design', 'person specification' and 'competency frameworks'

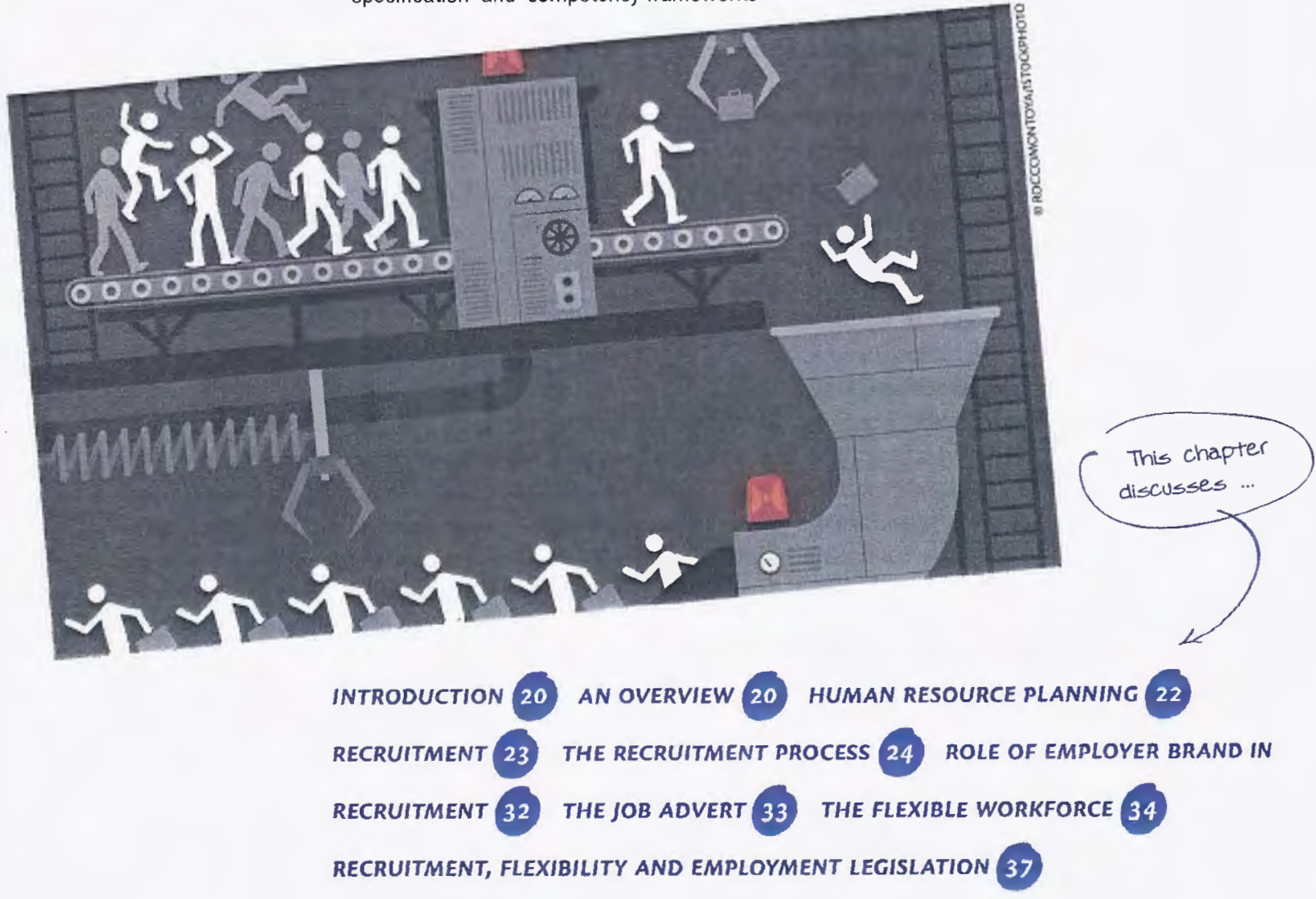


Over recent years, in the context of the global financial crisis and economic recession, the demand for and supply of labour have changed. The labour market has moved from being described as 'tight' to being described as 'loose'. A tight labour market is a seller's or jobseeker's market, where organizations find it more difficult to source employees due to high overall national employment levels. On the other hand, a loose labour market is a buyer's or employer's market, where organizations have a large pool of potential and available employees to hire for positions, since jobs are scarce, with jobseekers competing with many ochers for the same position.

A loose labour market, with high unemployment rates, has significant effects on the recruitment of staff, which include:

- a significant number of people applying for each vacant position

- wages can be reduced

- many of the people applying for scarce vacant positions are overqualified.

With this context in mind, in this chapter we look at human resource planning (HRP) in organizations and how an organization's human resource plans link in with its overall business strategy and corresponding recruitment strategy. First, we look at the key concepts of the chapter, namely HRP, recruitment and labour flexibility. Next, you will learn more about the different stages in the HRP process. Then we focus on the recruitment aspect. We go on to look at flexible work practices and the different types of labour/workforce flexibility. Finally, we consider legislation in the area of recruitment and flexibility of which you should be aware.

\section{AN OVERVIEW}

As Chapter 1 has underlined, people in organizations fundamentally influence business performance and impact on an organization's competitiveness. It is argued that people create the competitive difference, since other resources, such as technology, finance and raw materials, may be copied, but it is impossible to copy human beings (Pfeffer, 1994, 1995; Gratton, 2000). This makes the HRM function in organizations very important. Although

\section{SPOTLIGHT ON SKILLS}

1 You are aware that a positive employer brand provides an added incentive to candidates to apply for a position in an organization. Prepare a short report for your manager, outlining the Ieasons, in order of prionity, why the organization should focus on developing a positive employer brand. Suggest how your organization could improve its employer brand in practice.

2 You are working for a medium-sized organization in the manufacturing sector, which relies on a fulltime permanent workforce. Set out the business case for introducing the flexible firm model. What chalienges do you anticipate with implementing the flexible firm model? Outline the advantages and disadvantages of this model to the organization and to existing and new employees.

To help you answer the questions above, visit www.palgrave.com/business/carbery and watch the video of Olga Donnelly talking about recruitment.

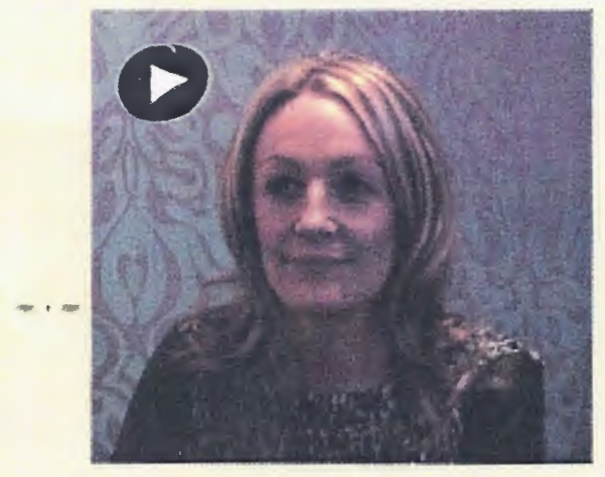

many of the traditional HR practices, such as recruitment, selection and performance management, are being devolved and managed to a large extent by line managers (Whittaker and Marchington, 2003), HR professionals are essential resources in an organization, as they hold specialist knowledge on the effective management of human resources.

It is fundamental that organizations consider and develop strategies concerning their present and future staffing requirements, with regards to the specific jobs and skills that are and will be required in their organizations. This is called human resource planning (HRP). Effective HRP is essential in order to avoid skills and/or staff shortages (or surpluses) in the organization. 
It ensures that the people employed in the organization have the skills the organization needs to be competitive. If the relevant skills are not available in-house, the organization may decide to train existing employees to develop those skills, or to recruit people with those necessary skills. The organization needs to consider how many people with different skills will be required for its different departments. For instance, if the organization determines to use more technology in coordinating its activities, it needs to ensure that sufficient numbers of staff are familiar with the particular technology, and may train existing staff members or recruit new employees who are already skilled in the use of that particular technology. Likewise, if an organization decides to strengthen its customer service focus, it must determine if it can train its existing staff up to the required customer service level, or if it needs to recruit new employees who already have customer service skills. In today's organizations, HR planning is increasingly looking at aligning HR policies and practices, such as recruitment, with the strategic aims of the organization.

However, the extent to which organizations can adequately plan for the future is contentious, since the unexpected may occur which can render plans useless. For instance, the extent of the global economic recession that started in 2007/08 was a shock for many organizations, forcing them to readjust their plans, with many having to postpone or downsize their expansion plans. Therefore, while planning is essential for organizations to prepare for the future, there must be flexibility inherent in the plans, should environmental conditions change that force the organization to reconsider its plans. Many organizations have contingency, or 'what if' backup plans that consider a variety of scenarios that may present themselves over time. However, organizations cannot spend all their time planning for all eventualities, but must make do with the most probable scenarios.

The recruitment process commences with HRP. Recruitment needs should be determined in line with the organization's current and proposed future business strategy focus in mind. In other words, the demand and supply of people with relevant skills in particular areas across the organization should match the organization's strategic intent. In keeping with the examples above, if an organization plans to use more technology, or strengthen its customer service offering and focus on customer service as a primary differentiator to competitors, the organization's recruitment strategy should reflect this, in the recruitment of people with experience of that technology, or the recruitment of qualified customer service staff.

Other practices, such as training staff in customer service innovations, also reed to be aligned with the organization's overall strategy. For instance, if an organization plans to strengthen its technology knowledge, or focus on customer service, this needs to be reflected in its training plans, where existing staff are trained in the new technology, or customer service respectively -Chapter 94. The strategic focus should also be measured during performance appraisals so that once the training has been completed, employee performance in working with the technology or in customer service is assessed. In aligning the focus on new technology or customer service with the organization's performance management Chapter 74, employees would be encouraged to be competent with the technology or in customer service, and the strategic importance of the use of new rechnology or superior customer service would be instilled in the mindset of the employees. These examples show how different HRM strategies - recruitment, training and performance management - need to be aligned with the organization's overall strategy.

In determining the organization's recruitment needs, the strategic options available, such as having a flexible workforce, also need to be considered. The organization may decide to recruit people on a full-time permanent basis, or on a part-time or temporary basis. With a loose labour market, organizations may opt for more part-time or temporary staff, while in a tighter labour market, the organization may be more inclined to offer permanent employment contracts in order to entice people to join the organization. For instance, during the global economic recession (2008-12), the public sector in many EU countries experienced employment control restrictions, limiting the recruitment of permanent staff. Such externalities, sometimes beyond the organization's control as in the case of the public sector hiring embargo (a freeze on hiring permanent employees in the public sector), influence the types of workers who are recruited (full time, permanent, temporary, fixed-term contract, or part time). We will be looking at labour flexibility and flexible 
work practices later on in the chapter. Thus, the macrocontext, exemplified in the example regarding the public sector hiring embargo, also needs to be considered in HRP.

We will return to and elaborate on the concepts of $H R P$, recruitment and labour flexibility later. Next, we examine the HRP process in more detail.

\section{HUMAN RESOURCE PLANNING}

You have learned that HRP is the continual analysis of staffing requirements, now and in the future, to ensure that the correct number of employees with the required skills are employed. HRP results in the development of specific HR strategies to achieve organization-specific staffing requirements. There are five key stages in the HRP process (Figure 2.1), which are described in detail below. These require HR planner(s) to:

1 analyse the current situation

2 forecast future staffing demand/supply

3 develop plans aligning current situation with future needs

4 implement plans

5 control, review and adjust plans (if needed).

As Figure 2.1 depicts, these five stages form a continuous process. This means that HRP is a cyclical process, with organizations engaging in HRP on an ongoing basis. We will look at each of these stages in more detail next.

\section{Analyse the current situation}

The first phase in HRP is to analyse the current situation with regards to the human resources in the organization.
This includes taking stock of the organization's existing employees and their details, such as name, length of service, organizational role, skill set, qualifications, training received, and performance reviews. This information, normally found in existing HR records, is of strategic relevance, in that it provides the organization with a wealth of data regarding the existing competencies and future potential of current employees. It informs the organization about the particular skills, educational qualifications and experience of the current workforce, which gives the organization an idea of where those employees could be deployed, that is, in which department(s) or area(s) they could work, in the future. In assessing the current situation concerning staffing, a job analysis is often undertaken. This is discussed in more detail later in the chapter.

\section{Forecast future staffing demand/supply}

Forecasting future staffing demand/supply is necessary, in that it forces HR planners to consider the future strategic orientation of the organization, and to identify the skills that will be required to fulfil that strategic direction, in what numbers, compared to the existing skills in the organization. From the organization's perspective, forecasting future demand for labour combines elements of subjective judgement (from the organization's management) and quantitative modelling, while forecasting future supply of labour involves an analysis of the internal and external labour markets. The internal labour market encompasses all those currently working for the organization. In analysing the internal labour market, factors such as retirement, staff turnover and promotion within the organization are considered. A clear outlook on these aspects should pinpoint potential areas where there could be skill shortages in the organization at

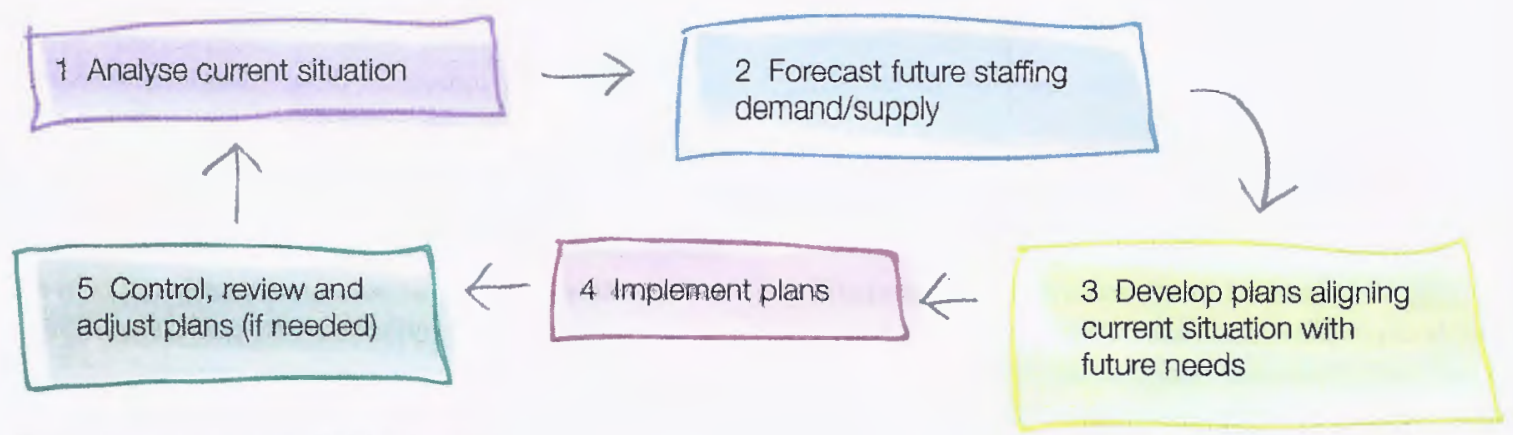

Figure 2.1 Stages in the HRP process 
a future point in time. With regards to the external labour market, the outlook for labour force participation rates the number of working age people available in a country or region and unemployment trends - can be considered. This helps organizations plan where they could be able to access new recruits in the future.

As you can imagine, this forecasting phase is difficult in practice, as there is always a risk involved in forecasting demand and supply: we cannot be 100 per cent sure what the future holds. The global financial crisis and economic downturn is one example of the challenge forecasting presents in reality. Had organizations globally forecast the financial crisis and economic downturn and planned accordingly, the mass closures and layoffs encountered by many organizations may not have materialized, or not to the same extent.

\section{Develop plans aligning current situation with future needs}

The third phase in HRP involves the development of plans to balance existing staff numbers and abilities with future requirements. This results in the formulation of plans concerning the types of people who may need to be recruited for particular jobs over time. The previous two stages involved identifying how HR needs are determined. This stage seeks to clearly lay out where skill shortages may be and how they need to be addressed in the organization's recruitment strategies, as well as showing where surpluses in skills may come about in the future.

In this context, eventualities are planned for with strategies such as the training (upskilling), redeployment or downsizing of existing staff that may be in the skills' surpluses area, succession planning to replace staff retiring or moving to other areas, and retention strategies to attempt to retain key skills in the organization where skills shortages exist. It is in this phase that the organization also considers its strategic approach to a flexible workforce, with regards to recruiting for full-time, part-time or temporary positions in the organization.

\section{Implement plans}

The fourth stage is the implementation stage, where the plans decided in stage 3 are put into action. These plans might concern recruitment, training or reorganization.
For the purposes of this chapter and the focus on recruitment, it is in this phase that the recruitment activities are implemented; for instance, when the job advertisement is created and advertised.

\section{Control, review and adjust plans (if needed)}

The final stage is where the implemented plans are reviewed and reconsidered with regards to their success, for instance in recruiting for particular positions in the organization. It is important to monitor how plans have worked out, to capture learning from previous activities. In this stage, it may be necessary to adjust the formulated plans or to reprioritize plans depending on how the plans are being fulfilled. For instance, if plans to recruit graduates for a particular department in the organization do not prove fruitful, the organization may be forced to reconsider these plans and potentially open the recruitment up to non-graduates or retrain existing employees.

Thus, the five stages are linked in the HRP process. Each stage is equally important in its own right. You can see the necessity for the HRP process to be aligned with the organization's overall strategy, so that the right jobs and people are hired and are in the right place, at the right time. Next, we take a closer look at what is involved in the recruitment process.

\section{RECRUITMENT}

Hiring people for deployment to positions within the organization is a fundamental HRM practice. Resourcing consists of two discrete components: recruitment and selection $>$ Chapter 34 . In this chapter we focus on the recruitment aspect, from HRP to specific recruitment methods. In Chapter 3 you will learn more about the selection aspect of resourcing, where the focus is on finding the most suitable person for the job in question from a pool of candidates.

Recruitment includes searching for and obtaining job candidates in sufficient numbers and quality, so that they feed the selection process. Once the pool of candidates has been collected, it is over to the selection process to filter these candidates further, shortlisting them until 
agreement is reached on which candidate(s) should be offered the position(s). The selection process is where the organization evaluates and decides who to employ for specific jobs/positions within the organization. It is important to note that recruitment and selection are discrete practices, and both need to operate effectively if the organization is to make optimal staffing decisions. The Consider This ... feature below explains why.

\section{(ONSIDER) THIS ...}

An organization may have an excellent system for evaluating and selecting candidates, but if the pool of candidates that come through the recruitment process is insufficient or of a low standard/quality, the resultant choice of candidate will not be optimum. Similarly, an organization may have an excellent recruitment system that resuits in a pool of highly skilled and competent candidates for an open position in the organization. However, if the selection process fails to undertake, for instance, due diligence in checking references and academic qualifications, the resultant choice of candidate will not be optimum. Therefore, while recruitment and selection are discrete practices within an organization, they are linked and depend on each other to ensure the best person is hired for the job in question.

HR professionals often work in cooperation with line managers in the relevant department(s) that are looking to employ someone new, in order to determine the most appropriate method of recruitment and selection. The aim is to attract the right numbers and types of candidates to apply for the vacant position. Line managers work with $\mathrm{HR}$ professionals in specifying the details regarding the position available and the type of skills and competencies required by the particular department to fulfil that position. The input from line managers in the recruitment and selection process is essential, since line managers know and understand the tasks involved in the role. Equally, they need to investigate if the new recruit will fit in with the rest of the team as regards their skills and experience. Line managers are also involved in the selection process, where they usually form part of the interview panel and ask job-specific technical questions.
For example, for an engineering position, where the HR manager may not have the technical knowledge regarding the specific skills required for the job, the engineering manager would play a key role in formulating the job description and person specification, as well as ultimately selecting the candidate for the position.

\section{THE RECRUITMENT PROCESS}

The recruitment process begins with a job analysis. Different jobs have different tasks associated with them, and conducting a job analysis allows you to gain detailed information about particular jobs, which is then used for recruitment, selection, performance management, reward management/compensation and training purposes in the organization. For instance, a job analysis for a teacher could identify tasks such as class preparation, communication with pupils and parents, attending relevant training activities to update skills, setring tests and marking work. It could also identify the need for the teacher to be qualified from an accredited institution and competent in the respective subject, to perhaps have previous teaching experience, to be a good presenter and communicator, to be an impartial marker and so on. This detailed information from the job analysis provides the basis for determining the recruitment and selection criteria, as well as the performance management, rewarding and training of the recruit. For instance, in our teacher example, they will be appraised in line with how well they fulfil the tasks required for the position. Depending on the experience and ability of the individual, their rewards and compensation will be determined accordingly Chapter $\mathbf{8 4}$. The training needs of the teacher will also be determined from the job analysis, where it will be identified if there are particular areas where the teacher should receive training and development in order to improve job performance Chapter 94.

When the organization knows what each job entails with regard to the tasks and skills required to complete that particular job, then the organization can plan how to staff that job accordingly. For instance, the organization could decide to train existing staff members to do the job, redeploy existing staff members from other departments where they are currently doing similar jobs, or recruit someone new to do the job. The decision 
depends on the skills available in the organization, the timing - if there is time to train someone in the organization to do the job or if there is a need for someone with the relevant skills to do the job as soon as possible - and the strategic relevance of the post - if the job is considered as core and long term, or if it is deemed more temporary in nature.

You could consider the job analysis to be like an audit of a job, detailing the different tasks the job entails as well as the particular skills and competencies needed to do that job. A job analysis results in both a job description and a person specification. In other words, after conducting a job analysis, you are in a position to write a detailed job description and person specification for the role, which form the basis for the job advert.

The job description is a detailed inventory of what a particular job entails. In the earlier example, this would include listing the duties a teacher would be required to fulfil, such as preparing classes and class plans, organizing parent-teacher meetings, setting and marking assessments and so on. The person specification addresses the kind of person the organization needs to do that particular job. In our teacher example, this would include details such as the educational qualifications and/or number of years' experience a candidate should have in order to be able to perform the job. The person specification, therefore, lays out the qualifications, knowledge, skills, personal attributes and experience required of an individual in order to match the particular job, some of which may be essential and others more desirable.

Many organizations search for the ideal candidate when they are writing the person specification, but it is important to differentiate between qualities that are essential for the role and those that are desirable. Focusing on too many 'nice to have' qualities is likely to limit the number of people who apply for a role. For instance, a person specification criterion for a particular position may be that it is essential to have an honours degree in HRM. In other words, anyone without an HRM honours degree would only be considered if the number of applicants in total was disappointingly low, but the organization needed to fill the position immediately, that is, is unable to wait for more qualified candidates to apply. The person specification should be developed from and accurately match the job description. Here, we provide an example of a job description and a person specification.

\section{Job Description: Student Union Senior Receptionist}

Post title: Senior Receptionist

Department: Student Union Centre

Responsible to: Student Union General Manager

\section{Purpose of the position}

- To provide and coordinate high-quality reception service.

- To provide general administrative support to Student Union officers.

Principal duties and responsibilities

- Organize reception duty on a rota basis and deal with general queries from students and the general public both in person, by telephone and via email.

- Direct the Union's customers to appropriate services in the SU.

- Maintain good presentation of reception and front of house.

- Deal with incoming and uulgoing post, ensuring it is correctly franked and despatchod.

- Sell and record ID card and SU ticket sales.

- Assist with the dissemination of information to students about Union services, events and activities.

- Work with Union departments to maintain a wide range of up-to-date, relevant information such as leaflets, booklets, posters and forms.

- Deal with poster stamping, flyer passes and any other general administrative tasks associated with counter duty.

- Use the public address system for messages to members and staff.

- Coordinate the booking of the Student Union facilities for meetings for internal and external customers. 
Other duties and responsibilities

- Open and close the Reception area as and when required.

- Work in a way that reflects the values of the organization as demonstrated in the SU Constitution, policies and strategic plan.

- Carry out duties with due regard to the SU Equal Opportunities Policy at all times.

- Act in accordance with the personnel policies and procedures as approved by the Staff Committee of the Union including Health and Safety Procedures and Staff Protocol Agreement.

- Act always in accordance with the financial regulations of the Union as outlined in the Constitution and detailed in the Financial Procedures Manual.

- Undertake such other duties as may reasonably be expected, given the incumbent's qualifications, experience and grade.

- Contribute to the positive image of the Union with students, university and community.

- Attend meetings and provide reports as and when required by the Union.

- Carry out the above duties at other sites of the university as necessary.

Person Specification: Student Union Senior Receptionist

Essential (E) or desirable (D) requirements

Qualifications that demonstrate proven numeracy, (English) literacy and keyboard skills

IT, typing or word processing qualifications

Experience of office activity, which must include receptionists' duties as well as clerical work

D

Skills, Knowledge and Ability

Ability to represent the Students' Union to staff and external contacts in a professional manner

Ability to handle difficult situations with tact, discretion and assertiveness

Ability to handle and accurately account for cash and resources

Ability to communicate, both in writing and orally, at all levels

Ability to undertake basic research tasks

\section{Personal Attributes and Attitudes}

Has a strong clistomer focus

Ability to work flexible hours

Trustworthy, reliable, approachable and flexible, with good attention to detail and demonstrable integrity

Ability to remain calm under pressure

Demonstrates a positive approach to best practice and exceeding customer expectations

Excellent customer care skills

\section{Excellent austomer care skills}

\section{BUILDING YOUR SKILLS}

Think about a job you are considering applying for after your studies and imagine that you are the line manager with responsibility for managing you, the new recruit. What would you list as essential and desirable in the job description and person specification for that particular position? Justify why you have listed certain tasks in the job description and certain skills/experience in the person specification.
As well as, or instead of, the person specification criteria, many organizations formulate competencybased criteria to filter candidates for particular jobs - Chapter 34. The Chartered Institute of Personnel and Development (CIPD, 2012b) defines competencies as: 'the behaviours that individuals must have, or must acquire, to perform effectively at work - that is, the ... focus [is] on the personal attributes or inputs of the individual'. Competency frameworks are developed for different positions in the organization. Competencies can include soft skills such as communication skills, presentation skills, leadership skills and collaborative skills (ceamwork). Whether certain competencies are 
desirable or essential will depend on the particular job; hence the importance of conducting a job analysis. For instance, if we return to the teacher example, the essential competencies for a Montessori teacher may differ from those for a secondary school teacher. Competencies such as flexibility and use of own initiative may be prioritized more for Montessori and junior school teachers, whereas the competencies for secondary school teachers, who are following a prescribed curriculum leading to state examinations, may include more of a focus on communication skills. The detailed inventory of the position and all it entails results in being able to establish the job description, person specification and the competencies, both essential and desirable, for that position. These are also often included in job adverts.

\section{CONSIDER THIS...}

Review the job advertisement section of a national newspaper. Note how many adverts include person specification details, competency frameworks or both. Are similar person specification criteria used for similar positions? Or across positions? What about competencies? Why do you think this is the case?

We now have all the information we need to begin recruiting for the position. Once a position has been identified as being vacant, the organization must decide on the method(s) to use in recruiting for that position. Different authors suggest different methods of recruitment. However, we can identify four broad methods: internal, external, online and overseas/ international, each of which are discussed below. You should note that the organization can use one or more (even all) of these methods in any one recruitment process. The choice depends on the amount of time and financial resources the organization has at its disposal for the purpose of recruitment. These four methods can also be collapsed into two main methods: internal and external recruitment, with online applicable to both and overseas/international applicable to external recruitment only.

\section{Internal recruitment}

Internal recruitment is a recruitment method where an open job position is advertised internally within the organization and current employees can apply for the position. This is also called the 'make' approach to recruitment, since it involves hiring someone to a new role from within the same organization.

There are many advantages of internal recruitment. It is cost-effective since the job vacancy advert can be posted on the intranet site (a form of e-recruitment), asking interested candidates to apply directly, rather than taking out expensive print media space. Internal recruitment advocates staff development and internal mobility in the organization. Existing employees gain the opportunity to move vertically to more senior positions through promotions, or laterally to enable employees to experience different roles in different departments. This opportunity to move internally can motivate existing staff to work towards achieving other positions in the organization. Loyal and hard-working employees are therefore rewarded. Internal recruitment is also advantageous for the organization in that the 'new recruit' is actually an existing employee, who is already familiar with the organizational culture, products and processes. This increases the probability of staff retention in the organization, with existing employees motivated by their potential to move to other positions in the organization. It also reduces the probability of early staff turnover of 'new recruits', since the recruits are from the internal labour market and are already familiar with and comfortable in the organization.

However, there are some disadvantages of internal recruitment. The primary disadvantage is that it limits the pool of applicants to those already employed within the organization. These employees may not have the skills and competencies required to perform the job to the highest standard. It also means that an existing employee, deployed through internal recruitment to another position, leaves a skills gap in the position they vacate, which may be more difficult to fill. Another key issue is that it can actually restrict innovation and diversity of mindset in the organization. This is because you are hiring people who are familiar with the organization and indoctrinated in its culture, and so are potentially unable to present novel approaches to performing in the position. The cost of training or upskilling an existing employee to fill a vacancy is a further disadvantage to choosing internal recruitment. While internal employees may feel motivated and empowered to apply for a new position in the organization via internal recruitment, these same employees may feel demorivared if cheir application is unsuccessful. This could cause a reduction in job satisfaction and ultimately a reduction in organizational productivity. 
Unprecedented numbers queued for hours to attend the Working Abroad Expo recruitment fairs in Dublin and Cork (Ireland) in March 2012. Thousands of visitors attended the fairs, along with their partners and children, in search of advice and, more importantly, jobs overseas.

Given the employment problems in Ireland, with over 440,000 people unemployed in a population of approximately 4 million, the Working Abroad Expo job fairs were considered by many as a rare sign of optimism that their skills and qualifications were still required globally, even if this was not the case in Ireland at present. Many wishing to attend the events had to be turned away, with advance tickets sold out.

In the Dublin Expo, the organizers charged $€ 10$ admission in an attempt to control the vast numbers of people attending, and to filter attendees to only those really interested in work overseas. Nonetheless, given the large attendance numbers, the event was described in some quarters as being more an emigration expo than a jobs expo. SGMC, the organizers, said it was the company's biggest ever event. Over 80 exhibitors from around the world, such as Canada, Dubai, Australia and New Zealand, as well as from other European countries, had stands. They were capitalizing on the recent impact of the global economic crisis in Ireland by marketing the job vacancies in their respective companies/countries. Advice and jobs were on offer to those interested in emigrating, and living and working in the various countries. Companies were recruiting for positions across sectors, including farming, mining, construction and healthcare; and across skills, including carpenters, fitters, machine operators, welders, mechanics and electricians. Large multinationals also exhibited, including Primark, PayPal, IN THE NEWS eBay and HewlettPackard.

Participants were advised to bring

their CVs with them to give directly to potential/prospective employers at the Expo. The exhibitors were looking to fill specific job vacancies and conducted interviews on the day at the event. Statistics given suggest that over 2,000 interviews were held at the Dublin event alone, with over 250 job offers made by the prospective employers/agencies attending/ exhibiting at that event.

According to the organizers, feedback from the exhibitors was that they were impressed with the people they met at the events and how they were able to recruit for specific positions in their organizations/countries and fill the vacancies/skills gaps in their organizations/countries. However, the lack of foreign language proficiency emerged as a stumbling block for the general Irish attendees seeking jobs. While Scandinavian exhibitors stressed that there were plenty of jobs available in their countries, the lack of attendees with the language competency required to work in those countries rendered many unsuitable for positions on offer there, or for any of the organizations requiring a specific competency/proficiency in an international language. Nevertheless, for the hundreds of attendees leaving the Working Abroad Expo with job offers, it was clearly well worth the queuing.

\section{Questions}

1 What method(s) of recruitment can you identify in the case study?

2 What advantages to this approach can you identify? What disadvantages to this approach can you identify?

\section{Sources}

Baker, N. (2012) Careers fair 'more

like an emigration expo', Irish

Examiner, 3 March, www.

irishexaminer.com/ireland/careers-

fair-more-like-an-emigration-

expo-185873.html.

Independent.ie reporters (2012) Up to 3,000 job seekers queue for working Abroad Expo in Cork, Irish Independent, 7 March, www. independent.ie/national-news/ up-to-3000-job-seekers-queue-forworking-abroad-expo-in-cork3042828.html.

Newstalk (2012a) Cork Work Abroad Expo extends hours until 9pm today, Newstalk.ie, 7 March, www.newstalk. ie/2012/news/cork-work-abroad-expoextends-hours-until-9pm-today/.

Newstalk (2012b) Over 12,000 attend Dublin Working Abroad Expo,

Newstalk.ie, 5 March, www. newstalk.ie/2012/news/over-12000attend-dublin-working-abroad-expo/. O'Brien, T. (2012) Fianna Fáil talks of its hopes for Ireland but nearby jobseekers look for a way out, The Irish Times, 5 March, wurw.irish times.com/newspaper/ireland/ 2012/0305/1224312795424.html.

O'Halloran, G. (2012) Thousands attend Working Abroad Expo in Cork City, The Irish Times, 8 March, www. irishtimes.com/newspaper/finance/ 2012/0308/1224313004039.html.

Riegel, R. (2012) 'There is no future here: we want a better life for our children', Irish Independent, 8 March, www.independent.ie/ national-news/there-is-no-futurehere-we-want-a-better-life-for-ourchildren-3043822.html. 
Internal recruitment is considered good practice, as it allows internal candidates the opportunity for lateral and vertical movement through the organization

- Chapter 104. In general, however, it is often the case that organizations use a combination of internal and external methods, as this is likely to produce the best possible candidates. We look at external recruitment in more detail next.

\section{External recruitment}

The second method of recruitment is external recruitment, also known as the 'buy' approach to recruitment. External and internal recruitment mirror each other in terms of advantages or disadvantages. The positive elements of one approach are the drawbacks of the other, and vice
External recruitment - a vacancy is advertised to potential candidates outside the existing employee base in the organization
Many organizations employ a less expensive form of external recruitment by using what are termed 'internal employee referrals' when seeking to fill a vacancy. Employee referral schemes work by inviting existing employees to recommend someone from outside the organization for the vacant position. This is a costeffective means of external recruitment as there are no external advertising costs involved. The internal employee receives monetary compensation for their recommendation if the proposed candidate proves successful and remains in the organization for at least a minimum period of time (often six months).

Additionally, the organization is more confident that the new recruit is suitable as the internal employee has recommended that person based on their prior experience of working with that person. The employee who made the recommendation will have a vested interest in ensuring their proposed candidate fits the organization, as the versa. External recruitment reaches a wider target audience, directly attracting potential candidates with the required person specification or competencies needed for the job. The training costs should therefore be reduced as the external recruit should already have the qualifications and skills required for the position. The external recruit should bring fresh blood, new skills and new ideas to the organization, which should improve orgarizational performance. This approach is also in keeping with promoting diversity in the organization. External recruitment can, if conducted well, improve the image of the organization in the wider community, as it presents the organization in a positive light by bringing employment to the local community.

There are a number of disadvantages, however, which involve the costs associated with external recruitment. There are the costs of placing job adverts in a variety of media outlets, such as newspapers or trade magazines.

Another expensive method involves the use of recruitment consultancies to attract candidates. Other costs include those of acculturating the external recruit to the organization's distinctive culture, products and processes. While every attempt will have been made to select the right candidate, the external recruit is, to all intents and purposes, unknown by the organization and may turn out to be unsuitable for the position and/or the organization. Recruiting externally can also demotivate existing employees who had applied for and hoped to get the new position. This demotivation and dissatisfaction can ultimately lead to problems with employee retention and increase employee turnover Chapter 41. success or failure of that recruit could ultimately affect the employee's monetary compensation for the recommendation and their reputation for reliability. It could also be expected that the proposed candidate will fit in with the organization's culture or way of doing business, as people usually associate with others of the same beliefs/values and so are more likely to recommend someone who will fit the organization.

Let us consider the following scenario. You have worked for the previous two summers as a promotions assistant in a marketing promotions and events management company. While doing this job, you frequently meet employees from different marketing companies, sometimes to work on the same event for a client. If a vacancy for a promotions executive arises in one of those other companies, an internal employee may recommend you as a porential candidate for the position. The internal employee is confident of your abilities, having seen your work in the past. You may be more interested in the position since you know that internal employee and have found out from them about the company and what it is like to work for it.

However, quality employee referrals may not be possible across all organizations. Smaller organizations, with fewer employees to begin with, may not have the social network capacity to recommend people for a vacant position. In tight labour markets, where skills shortages exist, many organizations make use of employees' social networks in urder to attract talent. The IT and telecommunications industries have widely used and continue to use the employee referral scheme to 
attract talented specialists to their organizations, in a win-win-win deal for the organization, the successful referral and the employee who made the referral.

\section{Formal and informal methods}

Both formal and informal methods are used when recruiting. Formal methods are those where the vacancy is officially advertised through a variety of media. Informal methods are those where candidates find out informally about a potential vacancy and apply for it. For instance, with external recruitment, the candidate can be made aware of the vacancy through word of mouth, employee referrals, or informal social media channels such as Facebook or LinkedIn. Candidates may also send spontaneous (unsolicited) applications. Formal methods, on the other hand, include advertising the position through different media (print, radio, TV, corporate website, recruitment-specific websites, social media) and/ or via employment/recruitment agencies. It would be usual for organizations to use a variety of such methods in their recruitment campaign in order to attract a wide pool of applicants from different sources.

Interestingly, research suggests that informal recruits often perform better than formal recruits (Barber, 1998). This could be because informal recruits take a more proactive approach to seeking to fill the vacancy because they are interested in the position and/or the organization. Formal recruits, on the other hand, wait until there is a position officially advertised before applying. They are more reactive, in that they react to the specific job advert before making their application. However, informal recruitment suggests a lack of consideration towards developing a diverse workforce, because it often brings in recruits who are similar in background and experience to the employees already in the organization.

\section{(ONSIDER THIS...}

What are the advantages and disadvantages of the different formal methods of recruitment (print, radio, $\mathrm{TV}$, online advertising and recruitment agencies)? Have you experienced any of these formal recruitment methods in your search for a job? Shortlist three or four criteria that could be used by organizations in determining which formal method(s) to choose.

\section{Graduate recruitment}

Graduate recruitment programmes take place when organizations visit the campuses of universities and other third-level institutions in order to attract graduates to apply to and join their organizations. In this way, the organizations go directly to the source for their recruitment purposes. It is categorized under external recruitment as it is effectively seeking to recruit someone from outside the organization. Alternatively, graduate recruitment fairs take place in a neutral venue where several employing organizations exhibit and present their business to graduates who may become recruits in the future.

Graduate recruitment is advantageous for an organization in that it allows that organization to costeffectively target qualified graduates to apply for open positions in the organization. By going directly to graduates in a certain discipline, such as business or IT, organizations seeking to fill positions in those areas have saved time, money and effort in seeking quality candidates for specific roles where such disciplines are essential. Graduate recruitment is also advantageous for the potential recruits/graduates as it allows them to familiarize themselves with different companies and the types of jobs on offer.

\section{Recruitment consultancies}

Some organizations avail themselves of recruitment consultancies, which manage the recruitment process for them. The outsourcing of recruitment to specialist agencies frees up HR resources in the organization and allows them to focus on other matters. For small organizations that may not have an HR department, the use of recruitment consultancies may be the most suitable approach. However, recruitment consultants are used by both large and small organizations.

For specialized positions, recruitment consultancies may have a database of potential candidates on file, which narrows the recruitment search - thereby saving time. This is particularly true in the IT and pharmaceutical industries or for accountancy and legal professionals, where the skills required are specific and possibly difficult to find. For senior-level recruits or where skills are in short supply, some recruitment consultancies offer an executive search or 'headhunting' facility, whereby they directly contact individuals with the skills a client organization is looking for. They do not have that individual's details on file, and the individual is not necessarily looking for a job, but the headhunter attempts to entice the skilled individual - with offers of better compensation and terms of employment - to at least apply for the open position in the client organization. 
Government agencies also provide a recruitment service, but these tend to be for lower level jobs. Such agencies have a comprehensive database of jobseekers and their skills/experience. They can then serve as the mediator between organizations seeking someone to work for them and the jobseeker. These public agencies offer back to work schemes to promote the employment of jobseekers.

\section{E-recruitment}

The third method of recruitment is e-recruitment. This method can be used alongside both internal and external recruitment, to create the most comprehensive recruitment process. Basically, e-recruitment is the use of the internet to aid in the attraction of candidates to apply for vacancies in the organization. Job adverts can be placed on the organization's intranet page (internal recruitment) or webpage (external recruitment), with details of the job description and person specification, and timelines for receipt of applications. The vacancy could also be posted on recruitment websites or through commercial online e-recruitment bodies that act as consultants and place the relevant job vacancy notice on different online websites for their clients for a fee.

The main advantage of e-recruitment is the size of the target market that can be reached, at a relatively low cost when compared to other external recruitment methods such as print advertisements. The speed of response also tends to be much faster through e-recruitment. CV filtering software is available that can help in reducing the numbers of initial applicants to a manageable list for selection purposes. Quite often, applicants need to complete an online application form with standardized questions and information requests. The software can then filter the applications using specific keywords based on different criteria, depending on the requirements of the client hiring organization. This can save time in filtering down candidates that apply for the position to those most suitable for the position.

The main disadvantage with e-recruitment, however, is the sheer number of potential applicants that result from an online job advert, which can then be difficult to filter and shortlist. Given the openness of e-recruitment, it can attract large numbers of underqualified candidares. There are also issues with security and data protection when applying for positions advertised online. Organizations cannot be sure that the information provided online by candidates is completely honest, but can only take that information at face value. This can result in a poor quality shortlist of candidates. Nonetheless, the growth of e-recruitment has been phenomenal, and is not expected to abate in the near future.

\section{Overseas/international recruitment}

The fourth and final recruitment method to be considered in the search for potential candidates is overseas or international recruitment. This method of recruitment is used particularly where the vacant position requires skills and/or competencies that are not readily available in the national context, so organizations resort to overseas recruitment in order to widen the pool of potential applicants.

The main advantage of overseas recruitment is that it increases the probability of finding the specific candidates required for the position.

For instance, in the IT sector, organizations may look to India with its large number of IT graduates for IT skills that may be in scarce supply among graduates in their own country. Organizations could attend graduate recruitment fairs in India in order to find candidates with the IT skills required. Earlier, HRM in the News presented an example of overseas recruitment with international organizations attending the Working Abroad Expo in Ireland in 2012 in order to attract educated and experienced applications for a variety of positions outside Ireland. International recruitment is often used for senior executive positions, where the best person for the job is sought, regardless of nationality. You can also see this in the international football arena, where managers of the national team can be recruited from different countries, provided their track record is positive.

However, the costs associated with overseas recruitment can be very high. If the candidates are shortlisted, the organization will have to cover transport costs for interviews and relocation. There may also be an issue with immigration laws and work visas, which the HR department would need to work through and adhere to.

Table 2.1 summarizes the main advantages and disadvantages of these four recruitment methods. Organizations should keep track of the recruitment method(s) they use and their respective effectiveness in attracting a pool of quality applicants for the relevant 
Table 2.1 Recruitment methods

\begin{tabular}{|l|l|l|}
\hline Recruitment method & Advantages & Disadvantages \\
\hline Internal recruitment & $\begin{array}{l}\text { Cost-effective } \\
\text { Form of staff development } \\
\text { Motivational tool } \\
\text { Increases probability of retention }\end{array}$ & $\begin{array}{l}\text { Limits pool of applicants } \\
\text { Not suitable where skill shortages } \\
\text { Can restrict innovation and diversity } \\
\text { Training costs may be high } \\
\text { Morale issues for unsuccessful internal applicants }\end{array}$ \\
\hline External recruitment & $\begin{array}{l}\text { Widens the pool of applicants } \\
\text { Reduces training costs } \\
\text { Advocates diversity } \\
\text { Improves employer brand }\end{array}$ & $\begin{array}{l}\text { Expensive to advertise externally } \\
\text { Candidates unknown to organization } \\
\text { Demotivating for internal employees }\end{array}$ \\
\hline E-recruitment & $\begin{array}{l}\text { Cheap } \\
\text { Access to large quantity of applications and } \\
\text { applicants } \\
\text { Speed of response }\end{array}$ & $\begin{array}{l}\text { Too many applicants } \\
\text { Security and data protection issues } \\
\text { Cumbersome to filter }\end{array}$ \\
\hline Overseas recruitment & $\begin{array}{l}\text { Access to larger quantity of candidates } \\
\text { Access to skill shortages } \\
\text { Access to best candidates internationally }\end{array}$ & $\begin{array}{l}\text { Custly } \\
\text { Increased administration work }\end{array}$ \\
\hline
\end{tabular}

positions. On application forms and/or new employee records, it could be recorded where/how the individual initially found out about the position. This information allows the HR manager/department to evaluate their most effective recruitment methods, by keeping track of the methods used combined with the successful applicants selected. This information can then be used by the organization to justify which recruitment method(s) to invest in and use in the future.

\section{BUILDING YOUR SKLLLS}

Think about a particular job you or a family member has had in the past (or currently has). As the line manager responsible for that particular job, what recruitment method or combination of methods would you use when hiring someone for that job? What factors influenced your choice of and decision regarding the recruitment method(s)?

Table 2.1 summarized the advantages and disadvantages of the four recruitment methods. You should remember that organizations may use one or all of these methods, depending on the amount of time and budget they have to fill the vacancy, and which method best suits the particular job

description and person specification for the vacant position. This will vary considerably between recruiting someone for a low-level production line job, where employee referrals may be used and prioritized, to recruiting a new football manager for the national team, where internal, external, e-recruitment and overseas recruitment methods may all be used. Once the decision regarding the recruitment method has been made, the organization must decide how it is going to attract candidates to submit their applications for the open position.

\section{ROLE OF EMPLOYER BRAND IN RECRUITMENT}

In order to attract the most suitable candidates for a vacant position, it is helpful for an organization to have a positive employer brand (Knox and Freeman, 2006; Mosley, 2007), which refers to their reputation as an employer. Being considered 'employer of choice' is positive for organizations, as it increases labour retention and attracts strong, talented applicants who want to work in such a positive environment. Recently, a variety of awards have gained

Employer brand - an organization is recognized in its own right as a desirable place to work - positive employer brand by the internal and external labour market prominence in this area such as the Great Place to Work Awards. Organizations such as Google or Microsoft would be considered as 
having positive employer brands. They have positive images as employers, offering competitive financial and nonfinancial rewards as well as structured internal career paths. Organizations with positive employer brands are considered 'good/great places to work'. Having a positive employer brand can often be seen in the amount of unsolicited applications an organization receives from people wanting to join that organization.

In tight labour markets, where there is a shortage of skilled applicants, it is particularly useful for organizations to have a positive employer brand so that they can better entice candidates to apply to join their organization. Informal methods of recruitment, such as spontaneous applications, often arise where organizations have a positive employer brand, as candidates are keen to join such organizations. The recruitment costs may fall as a result of having a database of potential recruits through unsolicited applications.

\section{THE JOB ADVERT}

As discussed earlier, the job description and person specification are the raw materials used in drafting the job adverts. Once the recruitment method is determined and the type of approach(es) to be used agreed upon, the job advert must be shared with the potential candidates. The job advert will include the relevant information concerning the position, such as:

- name of organization

- job title

- duties

- essential skills/competencies required

- desirable skills/competencies

- the application details (if the candidate needs to send a CV, cover letter, or if they need to complete an online application form)

\title{
Senior HR Administrator
}

\author{
Reference code: XX-OO-11-22-33
}

Location: London

Salary: £20k to £30k p.a.

Job type: 2-year fixed-term contract

Education level: Degree in HRM

Contact: A. White

The client: Our client is a leading multinational and is currently looking for a HR Administrator for a 2-year fixed-term contract role.

\section{Job responsibilities}

- Operation and maintenance of interview schedule

- Screening CVs for vacancies

- Updating employee HR system including setting up new employees

- Management and filing of interview notes in line with legislation

- Taking minutes at internal meetings

- Provide administration assistance to the managing director

- Preparing and coordinating group meetings

- Coordinating social events and company initiatives

- Administering monthly expenses
Skills and experience required

- Degree in Human Resource Management, minimum 2(1) award

- 1-3 years' experience in an HR environment

- Ability to deal with sensitive/confidential issues

- Excellent written and verbal communication skills

- Strong attention to detail

- Ability to prioritize workload in a fast-paced environment

- Excellent working knowledge of Microsoft Office Suite, particularly Excel, PowerPoint and Word

- Prior experience working with an Applicant Tracking System 
- the closing date for applications

- the address/contact details where the application should be sent.

It is important that the job advert is placed in the most suitable medium. For instance, if you are looking for a legal expert, you would advertise in legal/law magazines and websites.

The job advert should be drafted using AIDA criteria attention, interest, desire and action. In other words, the job advert should gain the attention of potential candidates. It should then rouse their interest in finding out more and reading through the details of the job advert. The job advert should instil desire in the potential candidate to want to fill that vacancy. This leads to action - the candidate applies for the position.

\section{(ONSIDER THIS ...}

Review some job adverts in the recruitment section of a local or national newspaper. What common information do they include in the job advert? Compare them using AIDA criteria from your perspective.

Now we move on to the flexible workforce and flexible working practices, and look at the type of employment contracts organizations can offer new recruits.

\section{THE FLEXIBLE WORKFORCE}

A strategic decision that an organization makes with regards to its recruitment strategy includes considering a flexible workforce. When sourcing people to take up positions in the organization, and after having conducted the research required as part of $H R P$, the organization may decide that it needs to employ someone on a temporary/fixed-term contract basis, a part-time basis, or a permanent longterm contract as required. In recessionary times, where there is a loose labour market and much market uncertainty, organizations may decide to hire more temporary or part-time staff. In so doing, the organization's obligations in terms of redundancy payments would be less should the organization need to cancel that job in the short term. This reduces the risk for employers. When deciding on the degree to which the organization will have a flexible workforce, it will determine the necessity for a core and peripheral workforce, and the types and degree of workforce flexibility required. Atkinson (1984) is credited with the flexible firm model, which consists of two categories of workers - core and peripheral - each category demonstrating its own particular type of labour flexibility, as explained below.

\section{Core and peripheral workforce}

Core workers are in the primary labour market. Their skills and competencies are believed to be central to the success and strategic development of the organization, as they often possess firm-specific skills and knowledge. They are typically paid a regular salary, benefits, receive training and development, have defined career paths with promotion opportunities and are involved in a performance management system. In return for their job security (permanence), they are considered most committed to the organization. Recently, due to intensive cost-cutting on behalf of organizations, there has been a shift away from the employment of core, full-time, permanent workers towards the employment of peripheral workers.

Peripheral workers are viewed as a method of keeping labour costs low in an organization. However, their skills and competencies are often needed on an ad hoc basis, such as to meet increasing demand at peak times, for example a retailer during the lead-up to Christmas, or for a specific shortterm reason, such as installing a new IT system. Peripheral workers include temporary, part-time, fixed-term contract, outsourced and selfemployed workers. They are part of the secondary labour market, where their employment is not secure or stable, but depends on market conditions. Peripheral workers lack firm-specific knowledge, have less 
job security and less opportunity for internal career advancement in the organization. There is often a high turnover of peripheral workers, particularly in a tight labour market - Chapter 34.

The main advantage of a peripheral workforce for organizations is costeffectiveness: the organization only employs and pays workers when they are required. This has become even more popular since the global economic crisis. One of the advantages for peripheral workers themselves is that this form of employment allows them to work on a short-term, fixed-term or part-time basis, and combine their work with other activities, such as childcare or studying. For instance, many students have part-time jobs while they are at university and/or take on temporary/fixed-term work over the summer vacation period. This allows students to gain valuable work experience and helps them pay for their education.

\section{Labour flexibility}

The need for flexibility across organizations has grown. Flexibility includes labour flexibility, the flexibility of technology, organizations and systems (Procter and Ackroyd, 2009: 495). It concerns the degree to which there is the ability to be adaptable depending on different circumstances, places and periods of time. Organizations that succeed in being flexible have a competitive advantage over those that are not, since flexible organizations can quickly adjust to changes in the environment.

With regards to labour flexibility, it is the organization's point of view that is normally considered. According to Atkinson's (1984) model, there are three types of labour flexibility: functional, numerical and temporal flexibility. Core employees provide functional flexibility. This means that organizations invest in training and developing their core employees so that they can meet changing demands for different skills or competencies. They are numerically stable, in that their number does not vary, but remains constant.

On the other hand, peripheral employees provide numerical flexibility, as the organization can increase or decrease the numbers employed depending on demand, over time. For instance, staff numbers are increased during busy periods and then reduced when no longer needed. People employed for numerical flexibility could be on short-term temporary contracts. Peripheral employees also provide temporal flexibility, in that their working hours can be adjusted, for example part-time or job-sharing positions. There is also an element of financial flexibility associated with the peripheral workforce. Organizations can more quickly and easily adjust the number of peripheral workers (numerical flexibility) and/or hours that peripheral workers work (temporal flexibility) in order to reduce (or increase) the respective wage costs (financial flexibility).

The use and size of the flexible workforce depend on a number of macro-level environmental conditions, such as legislation, levels of national employment (or unemployment), education and marketplace competition; as well as micro-level conditions, such as the size of the organization, the sector in which it operates, and the stage within the life cycle Chapter 14 .

\section{CONSIDER THIS ...}

Think of a part-time or fixed-term contract job that you or a friend or a family member has had. Compare that peripheral job with a core job in the same organization. What (if any) are the main differences? Do these substantiate the flexible firm model? If so, how? If no, why not?

\section{Criticisms of the flexible firm model}

The flexible firm model, while conceptually well accepted, has a number of critics who see it as a means for the organization to control the workforce, offering security to core workers in return for functional flexibility, at the expense of peripheral workers having their hours and numbers increased and decreased in line with the organization's needs. The peripheral workforce is also considered the 'atypical' workforce, which suggests the different status of positions held by core and peripheral workers, with the core workers prioritized with regards to 
initiatives such as training and development and/or promotions, it is argued that the flexible firm model breeds conflict between the different types of workers in an organization. The result is that one of these sets of workers' needs are prioritized over the other.

On the other hand, it has also been argued that functional flexibility leads to the intensification of work, with core workers expected to be functionally flexible and carry out different roles as part of their privileged position in the organization. Core workers can then be used on an ad hoc basis to cover skills shortages, such as holiday cover or sick leave cover, while continuing to do their primary jobs, and without receiving any additional compensation for this. This can lead to motivational problems and health and safety issues, with core workers potentially more stressed due to more demands on their skills.

The flexible firm model is also criticized for failing to address contemporary practices in HRM, where the gap between core and peripheral workers seems to be narrowing in practice. For instance, in periods of economic downturn, the number of core employees in an organization can be reduced in similar proportions to the peripheral employees, through downsizing and redundancy activities. The suggestion that core workers are more committed to their organization than peripheral workers is also contentious, in an era where individualism and boundaryless careers suggest the increased mobility of workers across the broad employment categories of core and peripheral - Chapter 104. In other words, the differences between core and peripheral workers seem to be diluted nowadays, where job security cannot be assured for any worker, core or peripheral. Today, job security is more aligned with market demand rather than residing in the core or peripheral workforce.

\section{Flexible work practices}

Flexible working practices refer to an organization's working arrangements in terms of working time, pattern and location of work and include practices such as teleworking, which enables employees to work remotely without having to be present in an office. Other flexible working initiatives include flexitime, where employees can choose when they start and end work, within broad time parameters. For instance, a family in which both parents work may avail themselves of flexitime so the father starts later and takes the children to school, while the mother finishes earlier to pick the children up from school. Job-sharing is a similar initiative where two employees share a particular job, with each of them potentially working alternate weeks or parts of weeks. Thanks to technology advances, which enable employees to access information remotely, from outside the office, more and more organizations are implementing flexible working practices, which enable their employees to balance their work and personal lives to a greater extent. There are also cost advantages for organizations, in that they may not need to provide office space for employees who work from home (telework).

These initiatives are promoted by organizations as part of a positive employer brand. Existing and potential employees often value flexible working practices as much as the other elements that make up the complete pay and benefits package $>$ Chapter $\mathbf{8} \mathbf{4}$. In this sense, the organization offers potential and existing employees a choice of flexible working conditions, such as job-sharing or working part time (often associated with women returning to work after maternity leave), teleworking (working from home, thereby reducing time spent commuting, or enabling parents to continue to work if they need to look after a sick child on an ad hoc basis), or flexitime (staggering the start times and finishing times in the office, provided the employee still works the required agreed average hours a week). Many employees enjoy the flexibility that this provides. For example, a programmer working for Nokia HQ in Finland can work remotely from their home in Mauritius on a daily basis, with only brief monthly trips to Nokia HQ required. In this example, the programmer is able to combine work with their personal pursuits (for example surfing in Mauritius).

Offering flexible working practices to existing and potential employees has met with primarily positive responses from employees, who see it as a way to balance work and personal life, as well as an opportunity to take control of when and where they work, provided the work gets done to the employer's satisfaction. Others, however, consider that flexible working practices have had a negative outcome for employees, with employees being constantly 'on call' through mobile and other technologies and, in effect, working longer hours as a result. There is a clear distinction between the benefits for employees of flexible working practices, which enable and facilitate work-life balance (chrough temporal flexibility and IT), and labour flexibility 
initiatives on behalf of organizations that seek to promote functional, numerical and temporal fexibility for the organization's advantage.

When undertaking recruitment, organizations need to determine the degree of a flexible workforce they wish to adopt, recognizing the associated advantages and disadvantages. Also, having a positive employer brand can assist in attracting a higher number of quality candidates. Offering flexible working practices is one means of developing a positive employer brand, since these are generally viewed favourably by employees.

We now turn our attention to key elements in employment legislation with which you should be familiar in regard to the recruitment function and the employment of flexible workers.

\section{RECRUITMENT, FLEXIBILITY AND EMPLOYMENT LEGISLATION}

Here, we consider some key elements in the employment legislation that are relevant in the recruitment stage, most notably the equality legislation. Since we also considered labour flexibility in this chapter, we include information on relevant legislation concerning part-time, fixed-term and agency employees as well.

When drafting job adverts and the terms and conditions of employment, the organization must abide by existing legislation. Of most significance is the equality legislation. All member states of the EU must adhere to anti-discrimination law and equal opportunities legislation $>$ Chapter 54 . The Equal Treatment Framework Directive (2000/78/EC) required the governments of all EU member states to draft anti-discrimination laws. EU anti-discrimination law ensures that potential applicants are not discriminated against on grounds of age, sex, sexual orientation, race/ethnicity/national origin, religion and disability. Specific to the Republic of Ireland in its Employment Equality Acts (1998-2008) is the protection against discrimination for members of an ethnic group known as the 'travelling community'. Employers must adhere to the anti-discrimination legislation relevant to their respective countries in order to protect employees/ potential employees against discrimination on the specific grounds listed above.

With regards to the flexible workforce, legislation also calls for equality of treatment across the different categories of workers (part-time, fixed-term and temporary agency employees). The EU Part-Time
Workers Directive (1997/81/EC) and the EU Fixed-Term Work Directive (1999/70/EC) ensure that part-time and fixed-term workers are treated comparably (pro rata) to full-time staff on permanent contracts. The EU Temporary Agency Work Directive (2008/104/EC) came into effect in December 2011. Although it was proposed in 2002, the British, German, Danish and Irish governments blocked its enactment until 2008. This calls for people employed in organizations through employment agencies to receive the same/equal treatment (equal pay and conditions) as employees of the organization doing the same work. These EU Directives stress the need for equal treatment of workers regardless of any physical differences or workforce categorization (core, periphery). For more details on EU legislation of relevance to recruitment and flexibility, refer to the EU legislation website, given below.

\section{$\Rightarrow$ SUMMARY}

This chapter focused on human resource planning and the recruitment aspect of HRM. We examined how HRP needs to be aligned with the organization's strategy so that the organization will have the right quantity and quality of employees it requires to operate a successful business, now and into the future. We set out the stages in HRP, describing important terms and concepts such as job analysis, job description, person specification and competency framework. We then moved our attention to recruitment, distinguishing recruitment from selection. We focused on the four recruitment methods, both formal and informal methods, open to organizations in attracting a pool of candidates to apply for a particular position, and the advantages and disadvantages of each method. We noted that more than one method of recruitment is often used by organizations, to attract the largest number of quality applicants possible. We also highlighted the relevance of a positive employer brand in attracting quality candidates. One of the important aspects in recruitment is the flexible firm model, which has both benefits and limitations. Finally, we identlfied the role that legislation plays in regards to recruitment (equality legislation) and flexible workers (part-time, fixed-term (temporary) and agency (contract) workers).

This chapter covered the recruitment part of the resourcing function. As you recall from earlier in the chapter, resourcing consists of recruitment and selection stages. Chapter 3 focuses on selection. 


\section{Recruitment Strategy at ValuOutlets}

Ann Yates is the HR manager at ValuOutlets, a firm in the food retailing sector in the UK and Ireland Following five years in $\mathrm{HR}$ in the hotel sector, Ann joined ValuOutlets a month ago, after achieving a first class honours Masters degree in HRM. She is enjoying the challenging role at ValuOutlets so far. While she is relatively new, her position is quite senior and she is the person responsible for HRM for the entire organization in the north of Ireland, with total staff numbers (full time, part time and fixed term) currently just over 50 . Her predecessor left the organization to take up a role in another organization.

While ValuOutlets is a relatively small organization, its strategic plan is to roll out more stores across the UK and Ireland. The organization is expanding and the senior management team wants to open a new retail outlet/store in a growing town in the north of Ireland. Ann Yates is tasked with determining the recruitment strategy and ultimately recruiting for this retail outlet. She calls together the small HR team (three others work in the HR department with her) to discuss the project and brainstorm how best to approach the recruitment strategy for the new store. She needs to present the proposed strategy to the senior management team at the end of the week. It will be her first presentation so she feels extra pressure in ensuring her proposed strategy is agreed on and signed off by the senior managers. She needs to decide if she will engage an external recruitment agency to take over the project completely, which could prove costly, or if she will handle it in-house.

There is a graduate student placement programme in operation at ValuOutlets, and this year the student placement is in Ann's HR department. She decides to dedicate that student to work on the recruitment strategy with her, allowing the other three members in the team to concentrate on their normal tasks. Together with the student, Ann considers how many

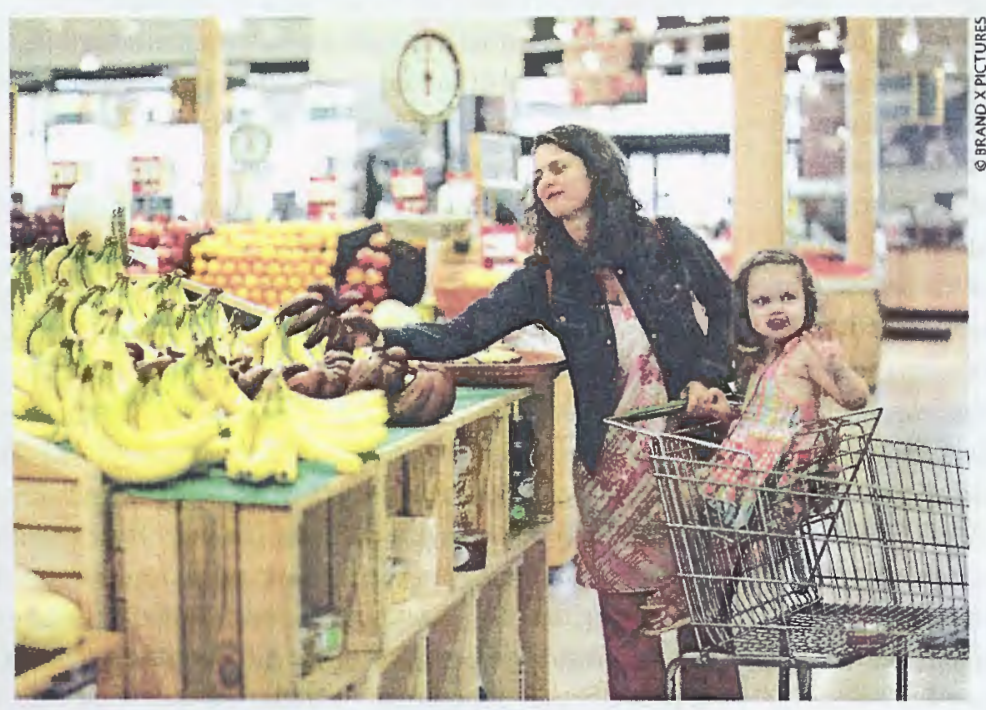

permanent, fixed-term and parttime staff members she will need to employ for the store. She must also determine the positions that need filling, from store manager, assistant store manager, to customer service and sales assistants.

Due to the heavy workload in the department and scarce resources, Ann decides to engage an external recruitment agency to manage the filtering of candidates for the open positions, resulting in the agency providing a shortlist of candidates, which must then go through the selection process. However, Ann must determine the recruitment methods and job advert to be used in recruiting for the store. Ann, with the student's help, pulls together her research and work into a presentation for the senior managers.

1 Weigh up the pros and cons of using an external agency to handle recruitment for the new store.

2 What do the student and Ann need to prepare in order to have a detailed overview of the positions required?

3 What factors do they need to consider in order to decide on the types of flexibility in worker categories they need for the various positions?

4 What recruitment method(s) could/should she choose, and why?

5 For the store manager job on offer, undertake a job analysis (job description, person specification, competency framework) feeding into the development of the job advert.

6 Given the growth plans of ValuOutlets, what other HR strategy reports should Ann consider preparing for the senior management team? 


\section{(HAPTER REVIEW QVESTIONS}

1 Why is it important for organizations to engage in HRP?

2 Describe how HRP is influenced by the organization's business strategy and recruitment strategy.

3 Differentiate between a job analysis, job design, person specification and competency frameworks.

4 Undertake a job analysis (job description and person specification) of any job of your choice. How well does the person specification match the job description? Can you see how the job description and person specification form the basis of a job advert? What other information may be required in a job advert?

5 Describe and differentiate between the four methods of recruitment identified in the chapter, presenting the advantages and disadvantages of each.

6 When should an organization employ the services of a recruitment agency?

7 Describe ways of generating an 'applicant pool' and attracting candidates.

8 What are the advantages and disadvantages of flexible working practices for organizations and for employees?

9 Under which conditions would you advise an organization to implement numerical, functional and temporal flexibility?

10 Outline the key equality legislation concerning the recruitment of core and peripheral workers in an organization.

\section{FURTHER READING}

Gunnigle, P., Heraty, N. and Morley, M. (2011) Human

Resource Management in Ireland: An Introduction, 4th edn, Dublin: Gill \& Macmillan.

Maund, L. (2001) An Introduction to Human Resource Management, Basingstoke: Palgrave - now Palgrave Macmillan.
Noe, R., Hollenbeck, J., Gerhart, B. and Wright, P. (2009) Fundamentals of Human Resource Management, 3rd edn, New York: McGraw-Hill.

Taylor, 5. (2010) Resourcing and Talent Management, Sth edn, London: CIPD.

\section{WWW USEFUL WEBSITES}

http://europa.eu/legislation_summaries/index_en.htm The Summaries of EU legislation website provides a database of EU employment legislation directives. Click on the relevant subject area.

www.ft.com/home/europe

Keep up to date with business matters through the Financial Times.

http://hr.com

HR.com has an online community and provides interesting fact files, surveys and case studies within the HRM domain.

www.irishtimes.com/jobsboard/

The recruitment page of the Irish Times website has numerous examples of job descriptions and person specifications.

www.monster.co.uk/

www.monster.ie

Monster's website is full of interesting links and articles on selection methods, such as telephone interviews, as well as an excellent example of an e-recruitment site.

www.peoplemanagement.co.uk People Management provides daily updates in the latest happenings in HR. Note that it is UK specific.

For extra resources including videos and further skills development guidance go to: www.palgrave. com/business/carbery

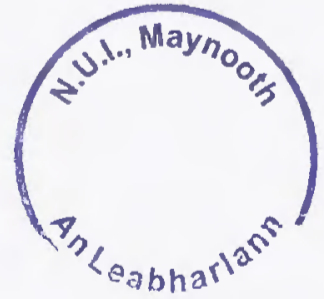

